\title{
Penerapan Konsep Finite State Automata Pada Aplikasi Simulasi Vending Machine Jamu Tradisional
}

\author{
Erni ${ }^{1}$, Fakihotun Titiani ${ }^{2}$, Sukmawati Anggraeni Putri ${ }^{3}$, Windu Gata ${ }^{4}$ \\ 1,2,3,4Sekolah Tinggi Manajemen Informatika dan Komputer Nusa Mandiri \\ e-mail: ${ }^{1} 14002422 @$ nusamandiri.ac.id, ${ }^{2} 14002417 @$ nusamandiri.ac.id, \\ ${ }^{3}$ sukmawati@nusamandiri.ac.id, ${ }^{4}$ windu@nusamandiri.ac.id
}

\begin{abstract}
Abstrak
Indonesia merupakan negara yang kaya akan budaya. Kekayaan budaya tersebut berlimpah ruah dan tidak terbatas pada kebiasaan masyarakat melakukan aktivitas tertentu maupun kerajinan tangan yang dihasilkan. Kekayaan budaya Indonesia juga dapat ditemukan dari olahan kekayaan alam yang ada di Indonesia, salah satunya adalah ramuan obat tradisional yang dikenal sebagai jamu. Jamu merupakan istilah yang digunakan untuk merujuk pada minuman obat tradisional asal Indonesia. Masyarakat Indonesia telah mengenal dan mengonsumsi jamu secara turun temurun. Selain untuk penyembuhan, konsumsi jamu juga ditujukan untuk obat penguat, penambah nafsu makan, serta obat pelangsing. Otomata adalah mesin abstrak yang dapat mengenali, menerima, atau membangkitkan sebuah kalimat dalam bahasa tertentu yang di dalamnya terdapat sebuah kajian tentang Finite State Automata yang dapat diimplementasikan dalam rancangan sebuah Vending Machine. Vending Machine di Indonesia banyak beroperasi dengan produk seperti makanan ringan, minuman, rokok, tiket, kopi, produk konsumen, bahkan emas. Dalam penelitian ini, akan diuraikan mengenai aplikasi simulasi Vending Machine jamu tradisional, berdasarkan implementasi Finite State Automata. Kesimpulan yang didapat dalam penelitian ini yaitu Finite State Automata dapat dijadikan sebagai logika dasar untuk membuat simulasi Vending Machine. Penelitian ini juga mengusulkan penggunaan state yang lebih sedikit, penggunaan uang kertas sebagai input dan kembalian untuk meningkatkan efisiensi dan biaya desain Vending Machine.
\end{abstract}

Kata Kunci: Finite State Automata, Vending Machine , Jamu Tradisional

\begin{abstract}
Indonesia is a country rich in culture. Greater cultural wealth is not limited to the habits of the people who carry out certain activities as well as the resulting handicrafts. The richness of Indonesian culture can also be found from the processed natural resources that exist in Indonesia, one of which is traditional herbal medicine known as herbal medicine. Jamu is a term used for use in traditional Indonesian medicinal drinks. Indonesian people have known and consumed herbs full of generations. In addition to healing, consumption of herbal medicine is also intended for strengthening drugs, appetite enhancer, and slimming drugs. Otomata is an abstract machine that can be approved, accepted, or asked for sentences in certain languages that are published about Countries Up to Automata which can be implemented in making Vending Machines. Vending machines in Indonesia are operated with many products such as snacks, drinks, cigarettes, tickets, coffee, consumer products, even gold. In this research, a Vending Machine Simulation application will be described, based on the implementation of Finite State Automata. The conclusion obtained in this study is that Finite State Automata can be made as a basis for making a vending machine simulation. This study also supports the use of fewer countries, using banknotes as input and refunds to improve the efficiency and design costs of Vending Machines.
\end{abstract}

Keywords: Finite State Automata, Vending Machine, Traditional Jamu

\section{Pendahuluan}

Indonesia merupakan negara yang

kaya akan budaya. Kekayaan budaya tersebut berlimpah ruah dan tidak terbatas pada kebiasaan masyarakat melakukan aktivitas tertentu maupun kerajinan tangan yang dihasilkan. Kekayaan budaya Indonesia juga dapat ditemukan dari olahan 
kekayaan alam yang ada di Indonesia, salah satunya adalah ramuan obat tradisional yang dikenal sebagai jamu(Nurwidodo, Mulyono, Fauzi, \& Husamah, 2018). Jamu merupakan istilah yang digunakan untuk merujuk pada minuman obat tradisional asal Indonesia (Gunawan \& Mustofa, 2017). Istilah "jamu" tersebut berasal dari kata "djampi" dan ditujuan untuk penyembuhan dan kesegaran tubuh (Tridjaja, 2017). Masyarakat Indonesia telah mengenal dan mengonsumsi jamu secara turun temurun. Selain untuk penyembuhan, konsumsi jamu juga ditujukan untuk obat penguat, penambah nafsu makan, serta obat pelangsing (Natadjaja, Tripoli, \& Wahyono, 2014).

Finite State Automata (FSA) merupakan salah satu komponen ilmu informatika yang memiliki fungsi-fungsi dari komputer digital. Menerima masukan, menghasilkan keluaran, bisa memiliki penyimpan sementara, dan mampu membuat keputusan dalam mentransformasikan masukan ke keluaran. Automata merupakan suatu sistem yang terdiri atas sejumlah state berhingga, dimana setiap state menyatakan informasi mengenai input sebelumnya, dan dapat pula dianggap sebagai memori mesin. Sedangkan teori automata adalah teori mengenai mesin-mesin abstrak, dan berkaitan erat dengan teori bahasa formal (Ma'arif \& Fauziah, 2018) (Abdullah \& Sari, 2014).

Otomata adalah mesin abstrak yang dapat mengenali (recognize), menerima (accept), atau membangkitkan (generate) sebuah kalimat dalam bahasa tertentu (Widyasari, 2011). Input pada mesin automata dianggap sebagai bahasa yang harus dikenali oleh mesin. Selanjutnya mesin automata membuat keputusan yang mengindikasikan diterima atau tidaknya input tersebut, sehingga mesin automata dapat dipakai untuk menghasilkan suatu bahasa yang aturannya ditentukan oleh bahasa tersebut(Suharsih \& Atqiya, 2019). FSA adalah model matematika yang dapat menerima input dan mengeluarkan output. FSA memiliki state yang berhingga banyaknya dan dapat berpindah dari satu state ke state lainnya berdasar input dan fungsi transisi. FSA tidak memiliki tempat penyimpanan atau memory, hanya bisa mengingat state terkini (W., Tolle, \& Setyawati, 2016). FSA merupakan pemodelan matematika dengan masukan berupa sejumlah himpunan terbatas. FSA juga memiliki sekumpulan state yang berhingga, sebuah state awal, dan fungsi transisi untuk berpindah state, serta himpunan bagian dari state untuk menerima hasil menjadi keluaran (Yohanes, Robert, \& Nugroho, 2017). Finite Automata, atau disebut NDFA merupakan salah satu mesin pada Teori Bahasa dan Automata, dipilih karena mudah untuk diaplikasikan dan sesuai dengan logika manusia juga merupakan tool yang sangat berguna untuk mengenal dan menangkap pola dalam data dan suatu graph berarah yang berfungsi untuk menggambarkan cara kerja suatu FSA, FSA juga di artikan sebagai model matematika yang dapat menerima input dan mengeluarkan output yang memiliki state yang berhingga banyaknya dan dapat berpindah dari satu state ke state lainnya berdasarkan input dan fungsi transisi (Kurniawan, 2012) (Aji, Sarwoko, \& Saputra, 2014) (Wirasbawa, Benedict, Santoso, Farhan, \& Kusnadi, 2019) (Maulana, Azizah, \& Kirana, 2020).

Mesin Penjual Otomatis Vending Machine (VM) merupakan sebuah kerja mesin penjualan yang akan mengeluarkan hasil barang atau suatu produk setelah pembeli memasukkan sejumlah uang kedalam kotak mesin yang telah tersedia(Sujana, Mardzotillah, Nuraidin, Rosip, \& Sulistianto, 2019). VM merupakan mesin penjualan makanan atau minuman yang berkerja secara standalone. VM merupakan penerapan dari bidang ilmu Teori Bahasa dan Automata yang dapat menjual barang atau kebutuhan manusia secara otomatis. Sistem penjualan dengan VM tidak membutuhkan operator, pembeli dapat memilih sendiri barang yang diinginkan. (Wicaksono, Amrizal, \& Mumtahana, 2019). VM pula merupakan suatu alat pemasaran untuk memasarkan suatu product didalam nya(Sujana, Hanipah, Dian, Suwenti, \& Aulia, 2019). VM atau mesin penjualan otomatis adalah mesin yang dapat mengeluarkan barang-barang seperti makanan ringan, minuman, rokok, tiket, produk konsumen, bahkan emas. Cara kerja vending machine layaknya penjual asli, mesin akan mengeluarkan barang yang kita inginkan setelah kita membayarnya dengan memasukan sejumlah uang kertas maupun alat pembayaran lain yang sesuai dengan permintaan vending machine tersebut (Sujana, Sari, \& Ulum, 2018). Perkembangan vending machine di Indonesia 
masih sangat muda. Vending Machine yang dapat menerima sistem pembayaran uang elektronik, contohnya e-money, flash, dan kartu elektronik lainya akan semakin popular dan semakin diterima di masyarakat. Keberadaan Vending Machine pastinya akan terus bertambah lagi dengan banyaknya variasi ataupun pilihan jenis barang yang diberikan dan bermacam macam nominal baik uang kertas maupun uang koin. Sebuah Vending Machine harus dapat melakukan proses transaksi penjualan yang sesuai berdasarkan pilihan yang diberikan pengguna dan dapat mengatasi permasalahan dalam VM maka akan digunakan penerapan konsep FSA pada VM untuk memodelkan proses transaksi secara otomatis(Suharsih \& Atqiya, 2019).

Dalam penelitian sebelumnya VM menggunakan FSA juga digunakan dalam aplikasi simulasi vending mesin antara lain sebagai berikut. Pada penelitian yang berjudul Penerapan Konsep Finite State Automata (FSA) pada Aplikasi Simulasi VM Yoghurt Walagri diterapkan pada penjualan yoghurt walagri otomatis dengan penggunaan state yang lebih sedikit, penggunaan uang kertas sebagai input dan kembalian untuk meningkatkan efisiensi dan biaya desain VM(Suharsih \& Atqiya, 2019), perancangan dan implementasi Finite Automata pada simulasi VM, dapat diambil kesimpulan bahwa Finite Automata dapat dijadikan sebagai logika dasar untuk membuat simulasi VM. Melalui aplikasi simulasi ini, diharapkan user dapat memperoleh pengalaman dalam mengoperasikan sebuah VM serta mengetahui cara menggunakan sebuah VM (Irawan, Pakereng, \& Somya, 2012), VM menggunakan non-deterministik finite outomata digunakan dalam aplikasi penjualan sereal dua pembayaran (Wirasbawa et al., 2019), Selain VM, dalam penelitian sebelumnya FSA juga diterapkan dalam Implementasi Sistem Monitoring Polusi Udara berdasarkan Indeks Standar Pencemaran Udara (Prahardis, Syauqi, \& Akbar, 2018), Implementasi Aplikasi Alat Bantu Pembelajaran (Jamilah \& Nurmansyah, 2018), dan Megimplemntasikan FSA terintergrasi dengan E-KTP FSA diterapkan pada penjualan rokok otomatis atau VM (Faisal, Saragih, \& Gata, 2020).

Dalam penelitian ini dibuat sebuah aplikasi simulasi VM yang dapat melakukan proses transaksi penjualan Jamu Tradisional seharga sepuluh ribu rupiah.
Aplikasi ini membutuhkan input berupa uang dan jenis jamu yang dipilih, sedangkan outputnya adalah tuju macam jenis jamu(jamu kunyit asem, jamu beras kencur, jamu presiden, jamu jahe, jamu temulawak, jamu cabe puyang, dan jamu pahitan) sesuai dengan pilihan pengguna beserta uang kembalian (jika ada). Uang yang digunakan adalah nominal lima sepuluh ribu rupiah, dua puluh ribu rupiah dan sepuluh ribu rupiah. Aplikasi ini juga dapat memberikan kembalian jika nominal uang lebih besar dari pada harga jamu yang dibeli. Tujuan dari penelitian ini adalah menerapkan konsep FSA pada aplikasi simulasi VM Jamu tradisional. Penerapan konsep FSA dipilih karena automata terbatas adalah mesin yang lebih sederhana, yang awalnya diusulkan untuk dimodelkan fungsi otak manusia(Ezhilarasu \& Krishnaraj, 2015). Untuk menggambarkan alur aktivitas VM, digunakan menggunakan Unified Modelling Language (UML) yang terdiri dari usecase diagram dan Activity diagram. UML adalah bahasa yang digunakan untuk menjelaskan kebutuhan, membuat analisa dan desain serta menggabarkan arsitektur(Maezar, Aji, Riyanto, Wijaya, \& Rudianto, 2018). Use case diagram menjelaskan antara pengguna dan sistem yang dibuat, sedagkan activity diagram menggambarkan aktivitas dari sebuah sistem yang dirancang(Wijaya \& Sari, 2015).

\section{Metode Penelitian}

Dalam sebuah penelitian, diperlukan adanya tahapan-tahapan yang tersusun dengan baik agar pelaksanaan penelitian tepat mencapai tujuan yang diharapkan. Tahapan yang dilakukan oleh penulis.

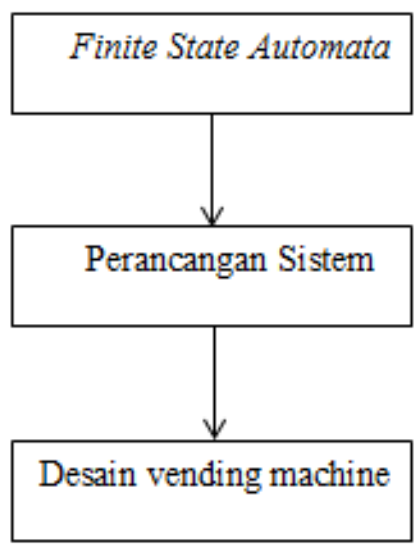

Gambar 1. Tahapan Metode Penelitian 


\section{a. Finite State Automata}

Dalam tahapan finite state automata penulis menggambarkan rancangan diagram transisi Diagram DFA.

\section{b. Perancangan Sistem}

Selanjutnya tahapan perancanagn sistem, penulis merancang sistem menggunakan UML yang terdiri dari use case diagram dan activity diagram.

\section{c. Desain vending machine}

Tahapan terakhir yaitu desain vending machine, disini penulis menggambarkan rancanagn desain antarmuka pada aplikasi simulasi vending machine jamu tradisional.

\section{Hasil dan Pembahasan}

\section{Finite State Automata}

FSA Merupakan model yang dapat menerima input dan mengeluarkan output yang memiliki state yang berhingga banyaknya dan dapat berpindah dari satu state ke state lainnya berdasarkan input dan fungsi transisi(Atina \& Oktaviani, 2019).

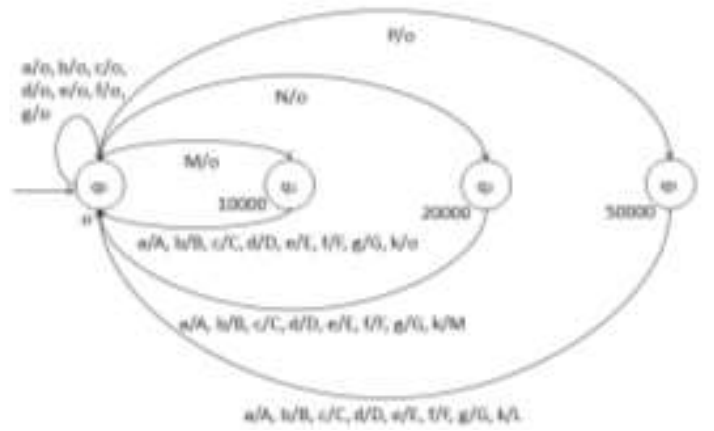

\section{Gambar 2. Rancangan diagram transisi} Diagram FSA

Pendefinisian Tuple Mealy machine didefinisikan dengan enam tupel.

$M=(Q, \Sigma, \delta, S, \Delta, F)$

dengan:

Q: himpunan state

$\Sigma$ : himpunan simbol input

$\delta$ : fungsi transisi

S: state awal

$\Delta$ : himpunan simbol output

$\mathrm{F}$ : state akhir

Sehingga dapat didefinisikan sebagai berikut:

$\mathrm{Q}=\{\mathrm{q} 0, \mathrm{q} 1, \mathrm{q} 2, \mathrm{q} 3\}$

$\Sigma=\{\mathrm{a}, \mathrm{b}, \mathrm{c}, \mathrm{d}, \mathrm{e}, \mathrm{f}, \mathrm{g}, \mathrm{M}, \mathrm{N}, \mathrm{P}, \mathrm{k}\}$

$\mathrm{S}=\{\mathrm{q} 0\}$

$\Delta=\{\mathrm{A}, \mathrm{B}, \mathrm{C}, \mathrm{D}, \mathrm{E}, \mathrm{F}, \mathrm{G}, \mathrm{O}\}$
Keterangan:
0 : Tidak ada
a : memilih jamu kunyit asam
$b$ : memilih jamu beras kencur
$c$ : memilih jamu presiden
$\mathrm{d}$ : memilih jamu jahe
e : memilih jamu temulawak
$f:$ memilih jamu cabe puyang
$g$ : memilih jamu pahitan
M: Uang sepuluh ribu
$\mathrm{N}$ : Uang dua puluh ribu
$P$ : Uang lima puluh ribu
$L$ : Dua lembar uang dua puluh ribu
$\mathrm{k}$ : Uang kembali

Terdapat sebelas input pada mesin ini, yaitu a (memilih jamu kunyit asam), b (memilih jamu beras kencur), c (memilih jamu presiden), d (memilih jamu jahe), e (memilih jamu temulawak), f (memilih jamu cabe puyang), $g$ (memilih jamu pahitan), $m$ (uang sepuluh ribu), n (uang dua puluh ribu), $\mathrm{p}$ (uang lima puluh ribu), $\mathrm{k}$ (uang kembalian). Sedangkan outputnya ada sembilan, antara lain A (mengeluarkan jamu kunyit asam), B (mengeluarkan jamu beras kencur), $\mathrm{C}$ (mengeluarkan jamu presiden), D (mengeluarkan jamu jahe), E (mengeluarkan jamu temulawak), $F$ (mengeluarkan jamu cabe puyang, dan $G$ (mengeluarkan jamu pahitan).

\section{Perancangan Sistem Vending Machine Jamu}

Sistem dirancang menggunakan UML yang terdiri dari use case diagram dan activity diagram.

1. Use Case Diagram

Sebuah use case diagram yang berfungsi untuk mendeskripsikan tindakan sistem dari sudut panang user, sebagai deskripsi fungsional dari sebuah sistem dan proses utamanya, serta menjelaskan secara visual siapa yang menggunakan sistem dan bagimana interaksinya. Aplikasi simulasi vending machine ini digunakan oleh user atau pengguna.

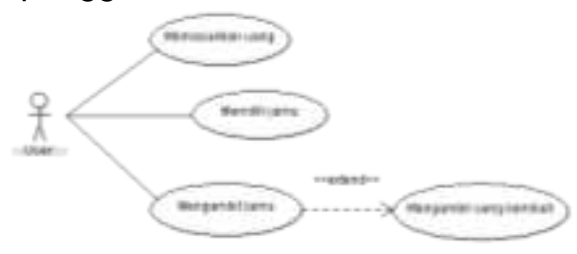

Gambar 3. Use Case Diagram untuk pengguna 
Pada gambar 3 menjelaskan tentang aktifitas diagram pada penjualan jamu tradisional dimulai dari user. User dapat masuk ke sistem, memasukan uang, memilih jamu, mengambil jamu dan mengambil uang kembalian.

\section{Activity diagram}

Activity diagram menggambarkan aliran aktivitas dalam sistem yang sedang dirancang,bagaimana masing-masing aliran dimulai, apa keputusan yang terjadi, dan bagaimana aktivitas tersebut berkhir.

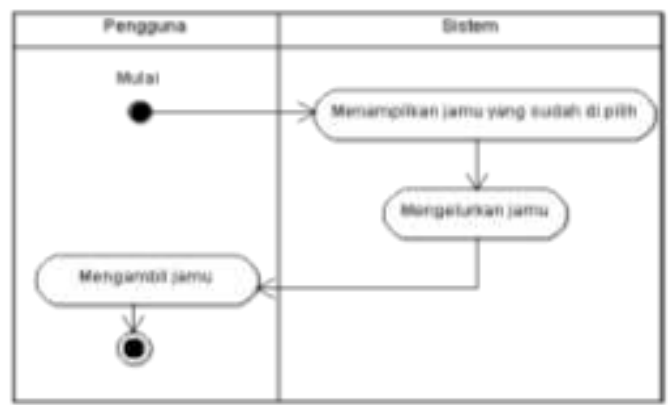

\section{Gambar 4. Activity diagram untuk pengguna memilih jamu}

Pada gambar 4 menjelaskan tentang aktifitas diagram pengguna memilih jamu pada penjualan jamu tradisional dimulai dari pengguna kemudian sistem menampilkan jenis jamu tradisional, selanjutnya pengguna memilih jamu yang diinginkan, sistem menampilkan jamu yang di pilihan dan selesai.

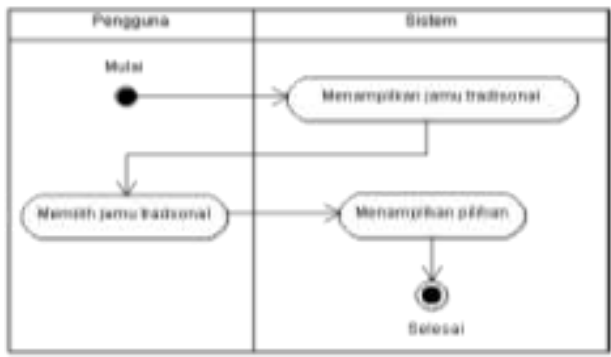

\section{Gambar 5. Activity diagram untuk pengguna memasukan uang}

Pada gambar 5 menjelaskan tentang aktifitas diagram pengguna memasukan uang pada penjualan jamu tradisional dimulai dari pengguna memasukan uang kemudian sistem menampilkan pilihan uang, selanjutnya pengguna memilih uang dan memasukan uang, sistem menyimpan uang, kemudian sistem menjumlahkan uang, mengeluarkan uang ketika ada kembalian, mengeluarkan jamu, jika uangnya pas langsung mengeluarkan jamu dan selesi.

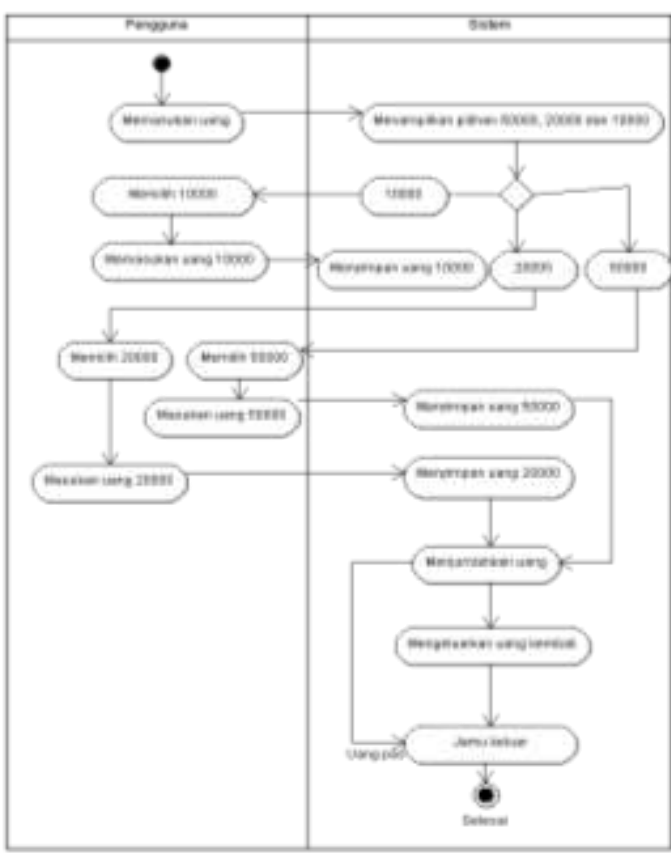

\section{Gambar 6. Activity diagram untuk pengguna mengambil jamu}

Pada gambar 6 menjelaskan tentang aktifitas diagram mengambil jamu pada penjualan jamu tradisional dimulai dari pengguna kemudian sistem menampilkan jamu yang dipilih, mengelurkan jamu, selanjutnya pengguna mengambil jamu, dan selesai.

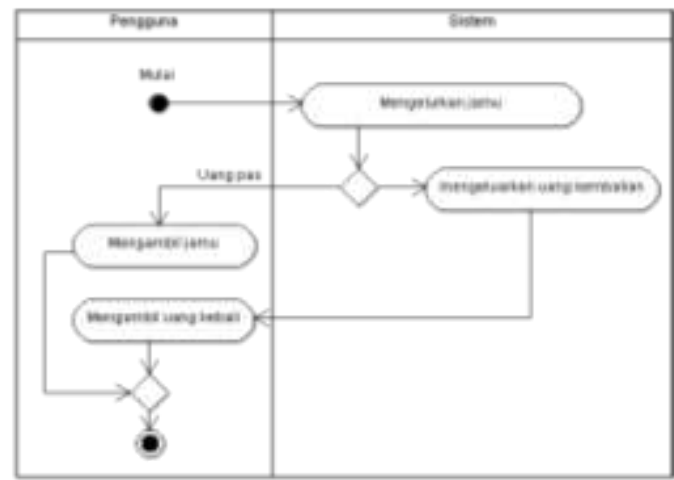

Gambar 7. Activity diagram untuk pengguna mengambil uang kembali

Pada gambar 7 menjelaskan tentang aktifitas diagram mengambil uang kembalian pada penjualan jamu tradisional dimulai dari pengguna kemudian sistem mengeluarkan jamu, ada percabangan mengeluarkan uang kembali selanjutnya pengguna mengambil jamu dan uang kembali, jika uang pas pengguna langsung mengambil jamu, dan selesai. 


\section{Desain Vending Machine}

Desain aplikasi simulasi vending machine jamu tradisional yang akan dibuat dapat dilihat pada gambar dibawah ini.

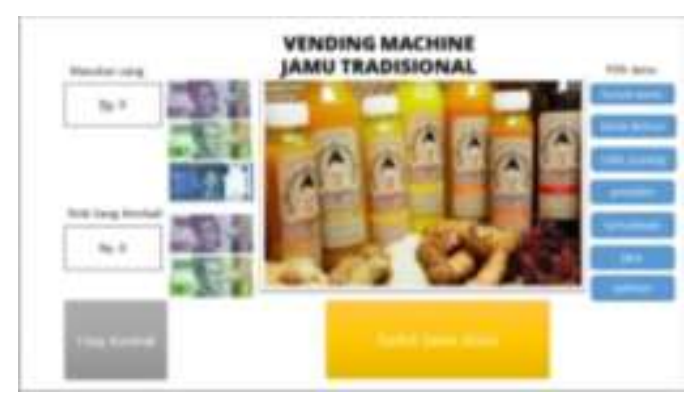

\section{Gambar 8. Desain VM Jamu Tradisional}

Pada gambar 8 desain VM jamu tradisional diatas menjelaskan tentang aktifitas pengguna dan aplikasi VM yang diawali dengan pengguna memilih jamu yang diinginkan kemudian VM menyimpan pilihan jamu, pengguna memasukan uang, VM menyimpan uang dan menghitung uang sesuai dengan jamu yang dipilih, kemudian VM mengeluarkan jamu, ketika uang yang dimasukan tidak pas maka VM akan mengeluarkan uang kembalian dan yang terakhir pengguna mengambil uang sekaligus mengambil jamu yang di beli.

\section{Kesimpulan}

Finite State Automata (FSA) dapat menjadi logika dasar untuk merancang suatu VM yang fleksibel dalam proses penjualan jamu tradisional dengan berbagai macam jenis dan variasi kembaliannya. Konsep FSA pada VM diterapkan dengan cara FSA membaca setiap simbol masukan yang diberikan menjadi suatu bahasa yang dikenali oleh FSA. Mesin selanjutnya akan melakukan proses pengeluaran jamu berdasarkan jenis jamu yang diinginkan beserta uang kembalian sesuai dengan bahasa yang telah dibaca oleh FSA. Penerapan konsep FSA dapat menjadi salah satu alternatif untuk merancang sebuah VM serta dapat dijadikan bahan pertimbangan dan acuan untuk pengembangan aplikasi selanjutnya yang sejenis.

\section{Referensi}

Abdullah, I., \& Sari, intan permata. (2014). Politik Identitas Masyarakat Perbatasan
Indonesia-Malaysia: Kasus Badau Di Kapuas Hulu, Kalimantan Barat. Jurnal Kawistara, $4(3)$. https://doi.org/10.22146/kawistara.6378

Aji, C. S., Sarwoko, E. A., \& Saputra, R. (2014). Aplikasi Konversi Aksara Latin Ke Aksara Jawa Menggunakan Finite State Automata Dengan Visual Basic. Journal of Informatics and Technology, 1(3), 5266. Retrieved from https://ejournal3.undip.ac.id/index.php/joi nt/article/view/6321

Atina, V., \& Oktaviani, I. (2019). Pakar Diagnosa Penyakit Radang Genetalia Interna Pada Wanita. Informa Politeknik Indonesia Surakarta, 5, 2442-7942.

Ezhilarasu, P., \& Krishnaraj, N. (2015). Applications of Finite Automata in Lexical Analysis and as a Ticket Vending Machine - A Review, 6(05), 267-270.

Faisal, A., Saragih, G. V., \& Gata, W. (2020). Desain Vending Machine Rokok Dengan Mengimplementasikan Finite State Automata Terintegrasi Dengan EKTP. Matics, 12(1), 55. https://doi.org/10.18860/mat.v12i1.8693

Gunawan, R., \& Mustofa, K. (2017). Finding Knowledge from Indonesian Traditional Medicine using Semantic Web Rule Language, $\quad 7(6), \quad 3674-3682$. https://doi.org/10.11591/ijece.v7i6.pp367 4-3682

Irawan, J. C., Pakereng, I. M. A., \& Somya, R. (2012). Perancangan dan Implementasi Finite Automata pada Simulasi Vending Machine. D'CARTESIAN, $\quad 1(1), \quad 42$. https://doi.org/10.35799/dc.1.1.2012.534 Jamilah, M., \& Nurmansyah, W. (2018). Rancangan Dan Implementasi Aplikasi Alat Bantu Pembelajaran Visualisasi Finite State Automata (Versi Pembuktian Graph ke Tupel). Seminar Nasional Teknologi Dan Bisnis, 204-215.

Kurniawan, D. (2012). Penerapan Konsep Finite State Automata ( Fsa ). Melly, Wamiliana, Kurniawan, 1(1), 95-102.

Ma'arif, R. A., \& Fauziah, F. (2018). Implementasi Finite State Automata (FSA) dalam Proses Pengisian Kartu Rencana Studi. JOINTECS (Journal of Information Technology and Computer Science), 3(3), 115-120. https://doi.org/10.31328/jointecs.v3i3.816

Maezar, A., Aji, B., Riyanto, V., Wijaya, G., \& Rudianto, B. (2018). Rancang Bangun Sistem Informasi Penjualan Produk Percetakan Berbasis Web Dengan 
Pemodelan UML, 8(1), 56-61.

Maulana, A. S., Azizah, H. N., \& Kirana, K. C. (2020). Implementasi Finite State Automata (FSA) dengan Simulasi Vending Machine pada Aplikasi Android. Jurnal Edukasi Elektro, 3(2), 110-120. https://doi.org/10.21831/jee.v3i2.28332

Natadjaja, L., Tripoli, F., \& Wahyono, B. (2014). The Ideal Female Body on the Packaging Design of Traditional Medicine ( Jamu ), (April), 51-59.

Nurwidodo, Mulyono, Fauzi, A., \& Husamah. (2018). Studi permasalahan pedagang jamu tradisional di Malang. Prosiding Seminar Nasional IV 2018: Peran Biologi Dan Pendidikan Biologi Dalam Revolusi Industri 4.0 Dan Mendukung Pencapaian Sustainability Development Goals (SDG's), 181-186. Retrieved from http://research-

report.umm.ac.id/index.php/psnpb/article/ download/2541/2374

Prahardis, R., Syauqi, D., \& Akbar, S. R. (2018). Implementasi Sistem Monitoring Polusi Udara Berdasarkan Indeks Standar Pencemaran Udara Dengan Pemodelan Finite State Machine. Jurnal Pengembangan Teknologi Informasi Dan Ilmu Komputer, 2(9).

Suharsih, R., \& Atqiya, F. (2019). Penerapan Konsep Finite State Automata (FSA) pada Aplikasi Simulasi Vending Machine Yoghurt Walagri, 1(2), 71-78.

Sujana, D., Hanipah, A., Dian, E., Suwenti, A., \& Aulia, S. Y. (2019). Analisis Vending Machine Menggunakan Metode Finite State Automata ( FSA ) Di Gedung Lama Universitas Islam Syekh Yusuf Tangerang. Jurnal KEILMUAN, 6(1), 1922.

Sujana, D., Mardzotillah, Q., Nuraidin, A., Rosip, M. A., \& Sulistianto, W. (2019). Komparasi Analisa Sistem Simulasi Vending Machine Automatic Cash Money Dan E-Money Di Universitas Islam Syekh Yusuf Tangerang, 7(1), 7-12.

Sujana, D., Sari, K. M., \& Ulum, N. M. (2018). Analisa Sistem Dan Implementasi Pada Vending Machine Red Boks Di Gedung A UNIS Tangerang Dengan
Menggunakan Metode Finite State Automata ( FSA ), 6(2), 67-70.

Tridjaja, Y. and N. O. (2017). Jamu-A Healthy Drink of Indonesia, 7, 221-226. https://doi.org/10.17265/21595828/2017.04.007

W., R. A., Tolle, H., \& Setyawati, O. (2016). Pengembangan Aplikasi Text-to-Speech Bahasa Indonesia Menggunakan Metode Finite State Automata Berbasis Android. Jurnal Nasional Teknik Elektro Dan Teknologi Informasi (JNTETI), 5(1). https://doi.org/10.22146/jnteti.v5i1.179

Wicaksono, T. H., Amrizal, F. D., \& Mumtahana, H. A. (2019). Pemodelan Vending Machine dengan Metode FSA ( Finite State Automata). DoubleClick: Journal of Computer and Information Technology, 2(2), 66-69. Retrieved from http://e-

journal.unipma.ac.id/index.php/doubleclic $\mathrm{k}$

Widyasari. (2011). Telaah Teoritis Finite State Automata Dengan Pengujian Hasil Pada Mesin Otomata. Jurnal IImiah SISFOTENIKA, 1(1), 59-67.

Wijaya, G., \& Sari, M. (2015). Perancangan Sistem Informasi Pengajuan Kredit Berbasis Web Pada PT. BPR Kredit Mandiri Indonesia Cabang Bekasi. IJSE - Indonesian Journal on Software Engineering, 3(2), 98-104. Retrieved from http://ejournal.bsi.ac.id/jurnal/index.php/ij se/article/view/3001/1938

Wirasbawa, N. D., Benedict, L., Santoso, B. G., Farhan, F., \& Kusnadi, A. (2019). Penerapan Konsep Non-Deterministic Finite Automata Untuk Pembuatan Sereal Menggunakan Mesin Jual Otomatis Dengan Dua Sistem Pembayaran, (November), 440-448. https://doi.org/10.30998/simponi.v0i0.375

Yohanes, B. W., Robert, T., \& Nugroho, S. (2017). Sistem Penerjemah Bahasa Jawa-Aksara Jawa Berbasis Finite State Automata. Jurnal Nasional Teknik Elektro Dan Teknologi Informasi (JNTETI), 6(2). https://doi.org/10.22146/jnteti.v6i2.306 